Review

\title{
Meteorological Knowledge Useful for the Improvement of Snow Rain Separation in Surface Based Models
}

\author{
James Feiccabrino ${ }^{1,2, *}$, William Graff ${ }^{2}$, Angela Lundberg ${ }^{3}$, Nils Sandström ${ }^{3, \dagger}$ and \\ David Gustafsson ${ }^{4, \dagger}$
}

1 Water Resources Engineering, Lund University, Lund S-221 00, Sweden

2 21st Operational Weather Squadron, United States Air Forces in Europe, Kapuan Air Base, APO-AE 09021, Germany; E-Mail: Graffmet11@gmail.com

3 Department of Civil, Environmental and Natural Resources Engineering, Lulea University, Lulea 971-87, Sweden; E-Mails: angela.lundberg@1tu.se (A.L.); nils.sandstrum@1tu.se (N.S.)

4 Research and Development, Hydrology, Swedish Meteorological and Hydrological Institute, Norrköping 601-76, Sweden; E-Mail: david.gustafsson@smhi.se

$\dagger$ These authors contributed equally to this work.

* Author to whom correspondence should be addressed; E-Mail: james.feiccabrino@googlemail.com; Tel.: +1-802-498-8980.

Academic Editors: Juraj Parajka, Cécile Ménard and Ladislav Holko

Received: 26 September 2015 / Accepted: 20 November 2015 / Published: 25 November 2015

\begin{abstract}
An accurate precipitation phase determination-i.e., solid versus liquid —is of paramount importance in a number of hydrological, ecological, safety and climatic applications. Precipitation phase can be determined by hydrological, meteorological or combined approaches. Meteorological approaches require atmospheric data that is not often utilized in the primarily surface based hydrological or ecological models. Many surface based models assign precipitation phase from surface temperature dependent snow fractions, which assume that atmospheric conditions acting on hydrometeors falling through the lower atmosphere are invariant. This ignores differences in phase change probability caused by air mass boundaries which can introduce a warm air layer over cold air leading to more atmospheric melt energy than expected for a given surface temperature, differences in snow grain-size or precipitation rate which increases the magnitude of latent heat exchange between the hydrometers and atmosphere required to melt the snow resulting in snow at warmer temperatures, or earth surface properties near a surface observation point heating or cooling a shallow layer of air allowing rain at cooler temperatures or snow at warmer
\end{abstract}


temperatures. These and other conditions can be observed or inferred from surface observations, and should therefore be used to improve precipitation phase determination in surface models.

Keywords: precipitation phase; snow; snow modeling; hydrology; meteorology; hydrometeorology; phase change

\section{Introduction}

The hydrological, ecological, and atmospheric responses to rain are extremely different from snow responses [1] and correct precipitation phase is, therefore, very important for applications across many scientific fields. Truthful identification of the precipitation phase (rain/snow) is of course crucial for the functioning of meteorological models that forecast the precipitation phase itself [2] but also for accurate correction of gauge measured winter precipitation [3] and for land surface models (LSM) predicting snow accumulation and melt [4], glacier and polar ice water balance models [5], models for lake and sea ice growth [6], and climate change models [7]. It is also important for models predicting avalanche hazards [8], sublimation of snow in forests [9], urban snowmelt quality [10], winter road safety [11], infiltration into frozen soils [12], survival of mammals and plants under snow cover [13], flooding from rain on snow events [14] etc. Precipitation phase determination is a modeling challenge for both hydrology and meteorology; therefore, a cross discipline approach combining methods and knowledge from both sciences could lead to new insight for both.

The International Association of Hydrological Sciences Decade on Prediction in Ungauged Basins (PUB) had the goal to improve basin hydrology through understanding processes rather than simply calibrating modeling schemes $[15,16]$. In ungauged basins, knowledge of processes would create more robust hydrological solutions compared to the traditional approach to calibrate parameters in one basin, and apply them in others without adjustments for landscape heterogeneity [15]. An example of a calibrated parameter used in many hydrological models is the precipitation phase determination scheme (PPDSs) usually based on surface temperature (the $2 \mathrm{~m}$ temperature reported from surface meteorological stations) relationships, ignoring important landscape and atmospheric interactions [17]. For example, compared to dry landscapes, open water and unfrozen wetlands add heat and moisture to sub or near freezing air in the lowest part of the atmosphere introducing variability into average atmospheric conditions across landscapes. For this reason, ice-free oceans were found to have a warmer PPDS threshold temperature than continental landscapes [18,19]. Therefore, it should be accepted that different PPDS schemes will be needed to account for lower atmospheric differences caused by variations in landscape. For example, dew point temperature based PPDS yielded less error than air temperature based PPDS in a saturated mountain environment [20], but an air temperature PPDS performed better in lower drier landscapes [21].

Within hydrological models, the PPDS are important [22], and many different schemes have been used. The most common approaches use surface air temperature $\left(T_{A}\right)$ e.g., [23] to determine the precipitation phase. Often $T_{A}$ and precipitation mass are the only measured variables with either lengthy enough historical records, or available at enough measuring stations for many studies requiring a PPDS [24]. Unfortunately, $T_{A}$ methods are not physically based as they do not attempt to incorporate 
physical processes present in the real world e.g., the effects of humidity on latent heat transfer [25] and other hydrometeor processes above the soil surface [26]. There are a few hydrological models that attempt to account for moisture in the surface-based PPDS by using surface dew point temperature $\left(T_{D}\right)$ [20], surface wet bulb temperature $\left(T_{W}\right)$ [27], and surface relative humidity $(R H)$ [1].

All surface-based PPDS approaches assume a constant decrease in air temperature with height (e.g., the Climate High Resolution Model (CHRM) $\left.-7.5^{\circ} \mathrm{C} / \mathrm{km}\right)[16]$ and do not account for interactions either between warm and cold air masses found in the most basic mid-latitude cyclone theories, or between hydrometeors and the air as precipitation falls through the lower atmosphere [28]. Therefore, without atmospheric measurements, the most physically based surface PPDS methods can not accurately reproduce physical processes occurring between hydrometeors and the atmosphere they fall through. The phase of precipitation at the ground can be univocally determined only by knowing the initial hydrometeor phase [29], hydrometeor shape and size [26], and the properties of the atmosphere through which the hydrometeor falls. These properties include above ground air temperatures $\left(T_{A G}\right)$, height of the $0{ }^{\circ} \mathrm{C}$ isotherm $\left(Z 0{ }^{\circ} \mathrm{C}\right)$ [17], vertical thickness of freezing and melting layers [26], atmospheric humidity [1], atmospheric stability [30], and interactions between hydrometeors [2,25,29,31].

The equations used for describing the microphysical processes evaporation, sublimation, freezing, and melting [26,29] acting on the falling hydrometeors are calculation intensive and require detailed atmospheric information often not included in current hydrological models [29].

However, some hydrological modelers have begun to integrate meteorological measurements, or add steps that indirectly account for atmospheric changes into their PPDS. These methods use $T_{A}, T_{A G}$, weather radars, or satellite images. Fassnacht et al. [32] and Gjertsen and Ødegaard [33] e.g., improved precipitation mass by integrating radar precipitation estimates into their hydrological models. However, they chose to use surface $T_{A}$ methods rather than differences in the properties of the radar return pulse that could distinguish precipitation phase.

This paper reviews and analyses studies dealing with precipitation phase processes and methods to determine the phase with an aim to suggest approaches that will improve the separation of rain and snow in cold region hydrological models. It starts with a basic overview of fundamental meteorological knowledge to build a baseline understanding of the physical changes between hydrometeors and air in the lower atmosphere. This first section builds to explain terrain/landscape, precipitation rate, and frontal boundary effects on the atmospheric temperature/moisture with height which has an impact on energy needed to drive phase changes in precipitation. This is followed by a short review of PPDS in atmospheric models and a longer review of current PPDS methods in surface models. The advantages and disadvantages of these PPDS methods are discussed along with a proposed formula to simplify surface air temperature-relative humidity PPDS schemes.

\section{Atmospheric Interactions during Phase Change}

In general, clouds and precipitation form when an air parcel rises and cools to saturation at the condensation level (the base of clouds). If snow falls through a warm atmospheric layer $\left(>0.0{ }^{\circ} \mathrm{C}\right)$ melting will begin $[25,32]$. Depending on air temperature, humidity and the thickness of a warm layer, 
latent and sensible heat exchanges between the snow and atmosphere could cause phase change from dry snow, to wet snow, to slush, to rain $[26,32,34]$.

Hydrological models based on surface weather observations do not have enough information to construct a vertical temperature/moisture profile that accurately reflects atmospheric conditions above the surface. A precipitation phase reported from a point location could be the result of many different atmospheric processes e.g., Stewart [25] explained that melting snow at the surface can be a result of (1) the melting process; (2) heat gained from collision with rain drops; (3) refreezing after partial melt; or (4) collisions with supercooled water. The assumption of any of these processes extrapolated over a model surface could lead to large errors. Therefore, the use of a vertical temperature/moisture profile of the environment is preferred in meteorology because it can first determine which hydrometeors are most likely to form in clouds, and then calculate any precipitation phase changes that might occur between and below the cloud level at which the hydrometeor formed.

\subsection{Lapse Rates}

Sampling instruments carried by weather balloons known as radiosondes provide vertical profiles of above ground air pressure, air temperature, dew point, wind speed/direction, and GPS location. Spatial resolution of the observations depends on the number of balloons launched in a given area. Over 800 stations worldwide submit radiosonde data for model intake. The time resolution is twice a day [35] at most locations. The vertical temperature and moisture profile gives useful information; e.g., freezing level height, actual lapse rate compared to the dry and moist adiabatic lapse rates [17], (Figure 1), and the depth of melting and freezing layers. Another reason to use radiosonde data for this application is that $T_{A}$ varies more than $\mathrm{T}_{A G}$ since the Earth's surface absorbs ultraviolet solar radiation and emits infrared radiation at different rates through the day. However, representative vertical temperature profiles may not be available at a necessary time, or for some areas the closest observation is hundreds of kilometers away and may not be representative for terrain or landscape induced variations in the lower atmosphere.

\subsection{Deviations from Average Lapse Rates}

The vertical temperature lapse rate under dry atmospheric conditions can be assumed to decrease steadily with height (Figure 2A). A similar assumption is implied through the use of set $T_{A}$ thresholds in hydrological models. These assumptions are incorrect when one or more of the following occurs in the near surface atmosphere; (a) the lapse rate is more unstable than average, decreasing the expected depth of a near surface warm layer (Figure 1); (b) there is an air mass boundary (Figure 2B,C); (c) falling snow is melting or refreezing (Figure 3); and (d) evaporation, sublimation, and/or condensation is occurring.

\subsubsection{Air Mass Boundaries}

Air mass boundaries introduce deviation from expected lapse rates due to a sharp increase or decrease in $T_{A G}$ (Figure $2 \mathrm{~B}, \mathrm{C}$ ). For a given $T_{A}$, this changes the probability of snow melting before reaching the ground. 


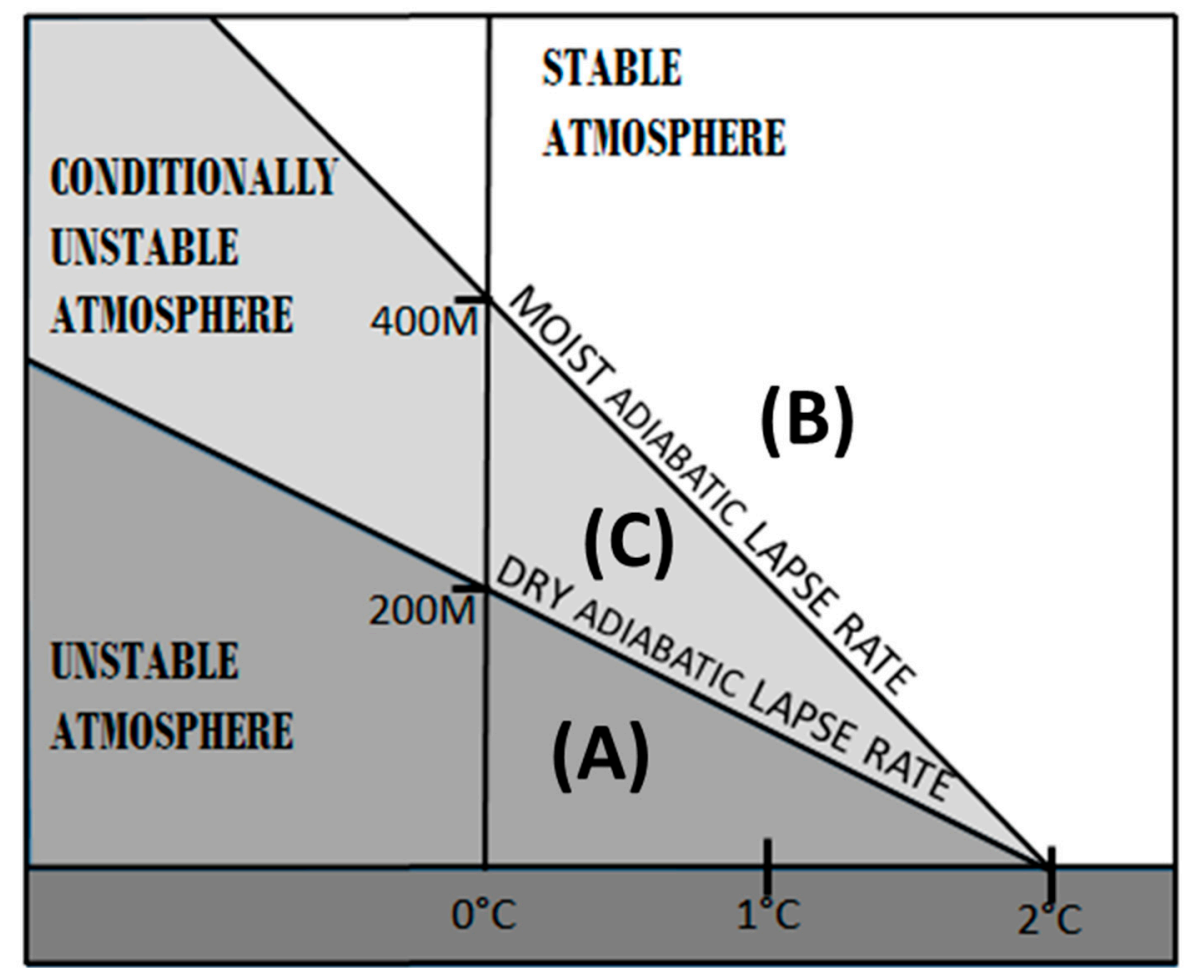

Figure 1. Dry $\left(9.8^{\circ} \mathrm{C} / \mathrm{km}\right)$ and moist $\left(5.9^{\circ} \mathrm{C} / \mathrm{km}\right)$ adiabatic lapse rates, give the expected cooling rates for rising air parcels without moisture or temperature advection. The dry and moist adiabatic lapse rates characterize the actual lapse rate as: (A) unstable when the actual $\mathrm{T}_{\mathrm{AG}}$ decrease is $\geq$ the dry adiabatic lapse rate $\left(9.8^{\circ} \mathrm{C} / \mathrm{km}\right)$. Here, an air parcel that is warmed or lifted will be lighter than the surrounding air and rise whether it is moist or dry. (B) stable when the actual $\mathrm{T}_{\mathrm{AG}}$ decrease is $\leq$ the moist adiabatic lapse rate $\left(5.9^{\circ} \mathrm{C} / \mathrm{km}\right)$. Here, an air parcel forced to higher altitudes (by terrain, or frontal lift) will be more dense than the surrounding atmosphere and will have a tendency to sink, even if condensation occurs; (C) conditionally unstable when the actual $\mathrm{T}_{\mathrm{AG}}$ decrease is between 5.9 and $9.8^{\circ} \mathrm{C} / \mathrm{km}$. Here, an air parcel must be forced to higher altitudes (over terrain or a frontal slope) to reach its condensation temperature. From that altitude, the moist adiabatic lapse rate decreases slower than the actual lapse rate. Therefore, an air parcel can become lighter than the surrounding air and rise freely.

\subsubsection{Isothermal Layers}

Melting and refreezing of falling snow causes a near-freezing $\left(+0{ }^{\circ} \mathrm{C}\right)$ isothermal layer $\left(D_{\text {melt }}\right)$ due to sensible and latent heat exchanges (Figure 3) [36]. This isothermal layer provides limited energy for phase changes, reducing the total amount of melting or refreezing caused by atmosphere-hydrometeor energy exchanges.

\subsubsection{Precipitation Intensity and Duration}

The depth of Dmelt increases with precipitation intensity and duration (Figure 3) [17,33,36]. Minder et al. [17] found that $D$ melt for very light precipitation was about $60 \mathrm{~m}$ and could exceed $300 \mathrm{~m}$ for high precipitation rates. 


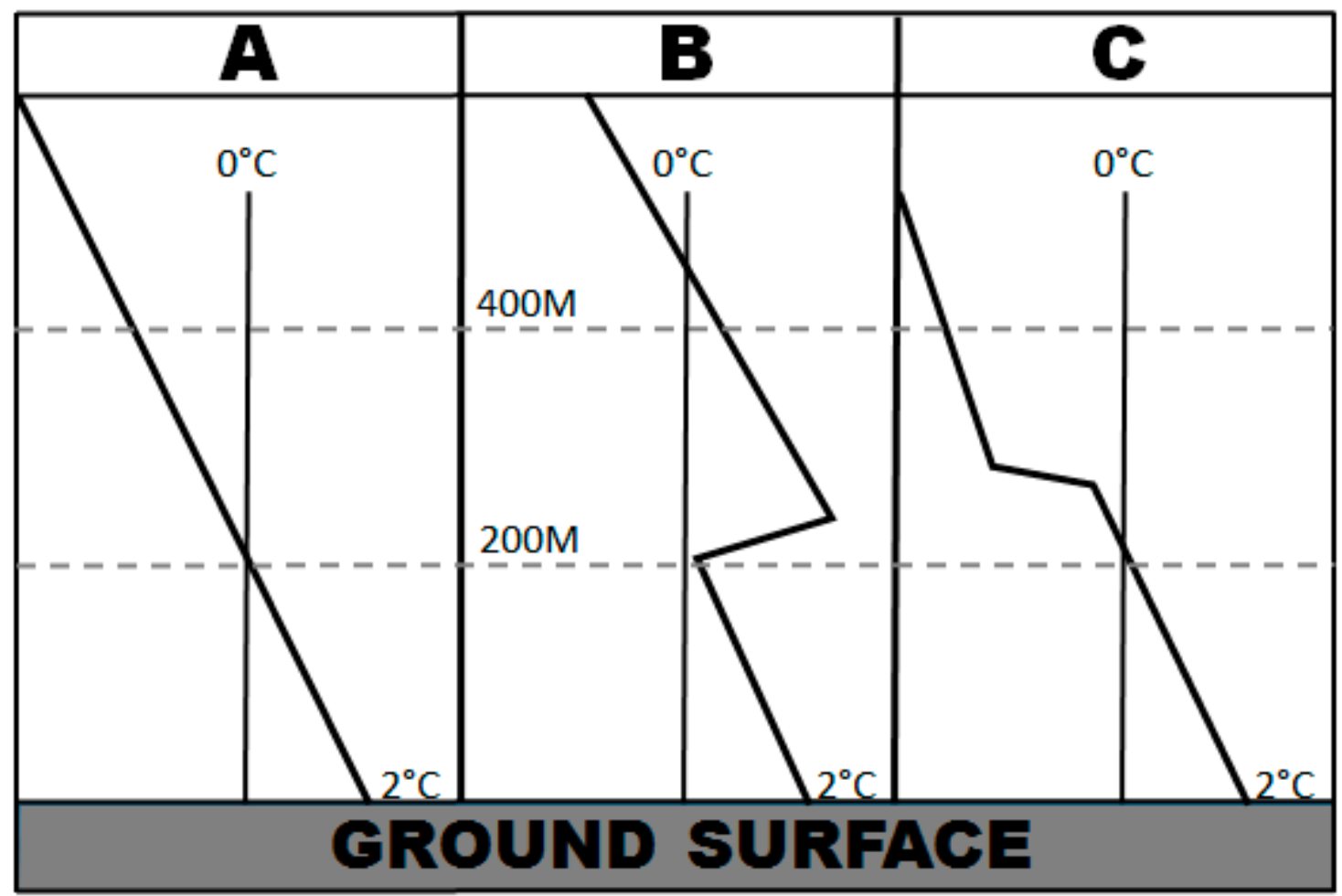

Figure 2. Examples of vertical air temperature profiles: (A) a single air mass with a constant lapse rate; (B) an air mass boundary separating a warm over cold air mass; and (C) an air mass boundary separating a cold over warm air mass.

Gjertsen and Ødegaard's [33] found that the above ground $T_{W}$ lapse rate decreased with increasing precipitation rates from 0.6 to $0.1{ }^{\circ} \mathrm{C} / 100 \mathrm{~m}$. The maximum $D_{\text {melt }}$ was $598 \mathrm{~m}$, and the minimum was $244 \mathrm{~m}$. However, Minder et al. [17] claims that $D$ melt is not an important factor since strong frontal winds usually restrict the average residency period of air in a melting layer to $10 \mathrm{~min}$.

Snow fractions for a given $T_{A}$ can be expected to increase with precipitation intensity and storm duration (Figure 3). Figure 3 illustrates differences between typical low intensity and short duration storms (Figure 3A) and high intensity or long duration storms (Figure 3B).

\subsubsection{Evaporation, Sublimation and Condensation}

Melting causes a $D_{\text {melt }}$ to form in the vertical profile that is usually a few hundred meters deep [37,38]. The thickness of $D_{\text {melt }}$ is dependent on snowflake diameter, relative humidity $(R H)$, precipitation rate, and the atmospheric lapse rate [17]. Mitra et al. [39] demonstrated that a $10 \mathrm{~mm}$ diameter snowflake would have a $D_{\text {melt }} 100 \mathrm{~m}$ thicker than a $5 \mathrm{~mm}$ snowflake during otherwise identical conditions. The sensible flux is dependent on the temperature difference between the hydrometeor and the ambient air while the latent heat flux is reliant upon the difference in vapor density (i.e., on $R H$ ) between the hydrometeor and the ambient air [20,29]. Sublimation $(2594 \mathrm{~J} / \mathrm{g})$ and evaporation $(2260 \mathrm{~J} / \mathrm{g})$ consume heat energy from the atmosphere reducing available melt energy ( $334 \mathrm{~J} / \mathrm{g}$ ) while condensation $(2260 \mathrm{~J} / \mathrm{g})$, ice condensation $(2594 \mathrm{~J} / \mathrm{g})$, and freezing $(334 \mathrm{~J} / \mathrm{g})$ release heat energy back into the atmosphere. Melting and refreezing may be combined with evaporation/sublimation, so that hydrometeor latent and sensible heat exchange is balanced by heat flux from the atmosphere. For moist air, i.e., air with high relative humidity, little 
evaporation/sublimation can be expected due to high vapor density surrounding the hydrometeor while more can be expected for dry air due to low vapor density around the hydrometeor [29].
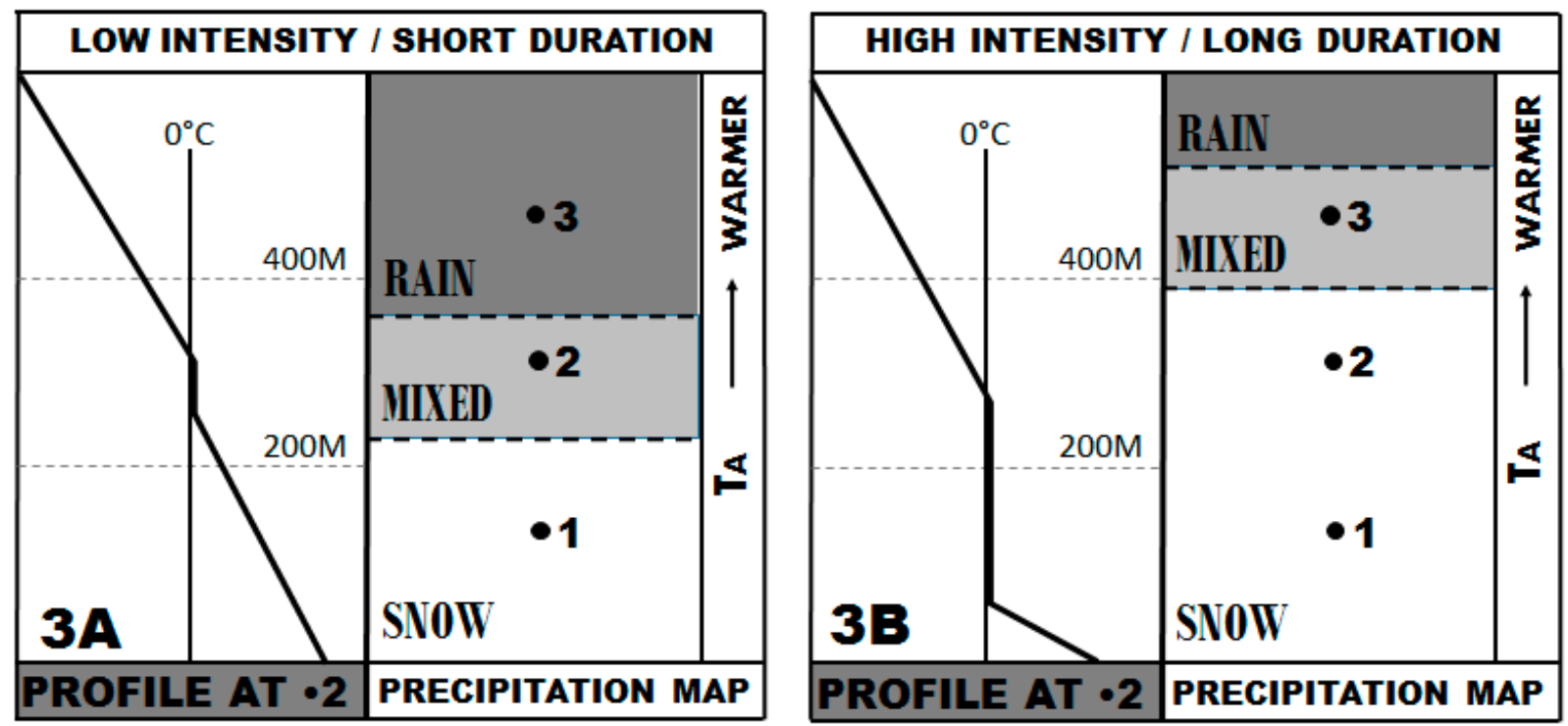

Figure 3. Overviews of flat areas are shown to the right in the two Figure 3A,B where initial storm conditions are the same but precipitation rate and duration differ. From bottom to top in the overview, surface temperatures increase to correspond with a precipitation phase change from snow to mixed precipitation to rain. The vertical profiles to the left in the subfigures illustrate the situation in location 2; (A) illustrates the situation for a low intensity or the beginning of a precipitation event, with a thin isothermal layer in the vertical temperature profile; (B) illustrates the situation for a prolonged or high precipitation intensity event. It has increased depth of the isothermal layer but minor change in surface temperature, a more unstable near surface lapse rate, decreasing melt and increasing surface snow areas.

\subsubsection{Hydrometeor Interactions}

If droplets freeze or ice crystals melt on a hydrometeor, they would release or absorb $334 \mathrm{~J} / \mathrm{g}$ of latent heat [25]. The melting rate of snowflakes thus increases when they collide with cloud or rain droplets [26]. This is because a hydrometeor composed of both liquid and solid fractions has a fixed temperature of $0{ }^{\circ} \mathrm{C}$ [25]. Snow colliding with rain or cloud droplets will undergo melting to chill the droplets to $0{ }^{\circ} \mathrm{C}[25]$.

The atmospheric physics of hydrometeor formation and interactions including phase change are very complicated. An understanding of the basic five equation microphysical schemes used by Stewart [25] is suggested. His equations account for: (1) Heat exchange resulting from gas, liquid, or solid phase change; (2) Change in particle mass by condensation; (3) The resulting latent heat flux from condensation; (4) Heat exchange from collision coalescence or through accretion of liquid and ice crystals; and (5) Latent heat of fusion with particles melting or freezing due to contact with each other. Detailed examples of more complicated microphysical schemes are found in e.g., Thériault and Stewart [26] or Lundquist [28]. 


\subsubsection{Terrain Influence}

Topography plays an important role in the surface location of rain/snow phase transitions. It is common for phase transition to be associated with a shallow cold layer beneath a warm layer on the lee side of mountains. This is known as cold air damming. This phenomenon can lower $Z 0{ }^{\circ} \mathrm{C}$ [17,25], and may add an extra freezing level in the vertical temperature profile (Figure 4). A phase transition region can sometimes be linked to coastlines due to warm sea surface temperatures. The warm water transfers heat to the near surface atmosphere increasing the available melt energy over the open water, also extending into the near coastal region. Strong winds can push this warm air further inland or offshore, therefore, also moving the location of a phase transition region [25]. In most cases, a phase transition region will progress towards adjacent rain areas (Figure 3) [25].

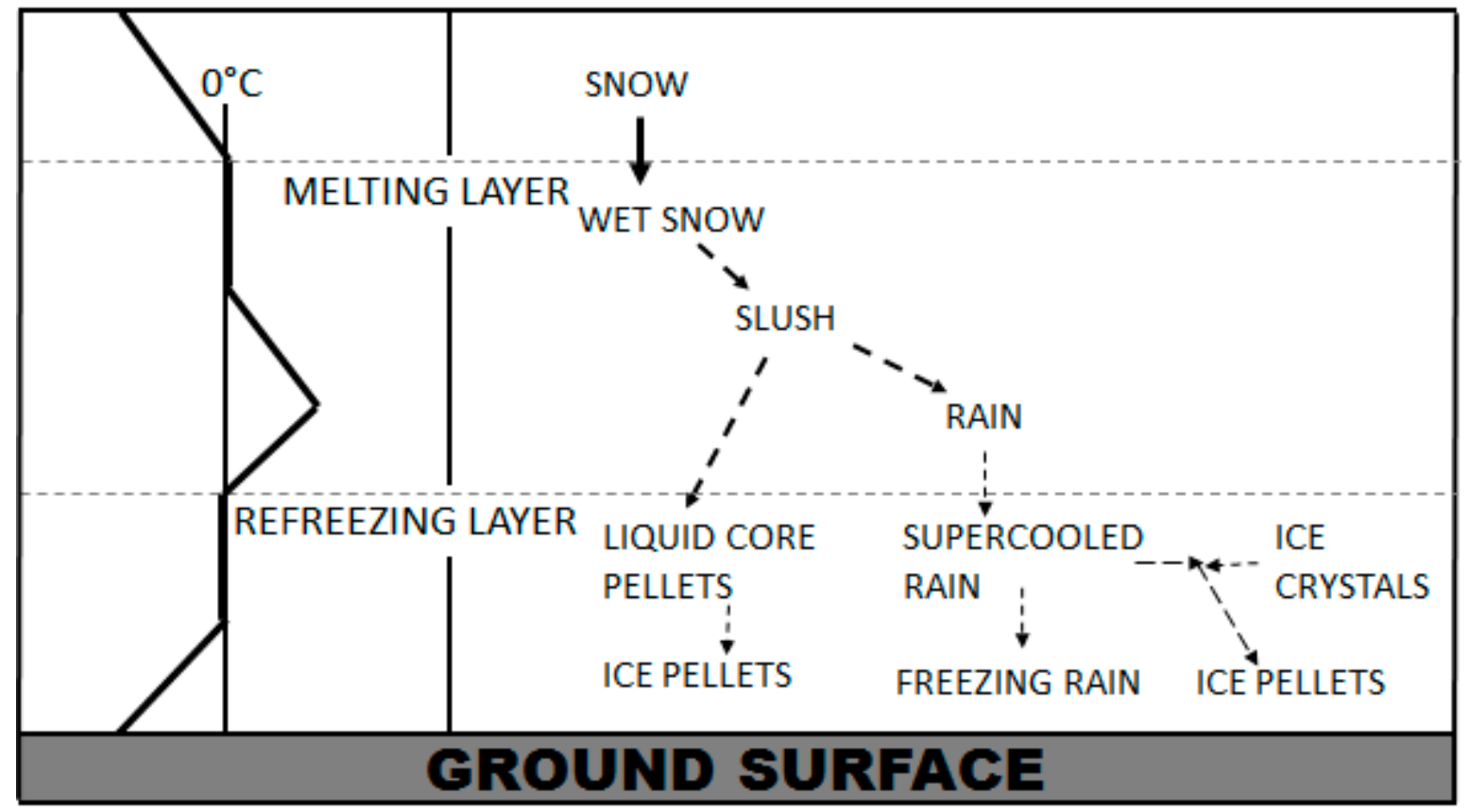

Figure 4. Phase changes of snow in a melting layer, followed by phase changes in a refreezing layer modified from [26].

Air forced to rise over terrain obstacles may also yield orographically enhanced precipitation. Increased precipitation rates cause a thicker $D_{\text {melt, }}$ lower $Z 0^{\circ} \mathrm{C}$ and snow elevation $(\mathrm{Zs})$ than upwind [17]. This lowering of $Z 0^{\circ} \mathrm{C}$ and $Z_{S}$ will introduce phase errors in a model that simply projects temperature heights from a sounding (or snow elevations from radar returns) without adjusting for variations in terrain. The magnitude of change in $Z 0{ }^{\circ} \mathrm{C}$ and $Z_{S}$ depends on the geometry of the terrain and the properties of the melting layer (including both $R H$ and wind speed) [17].

\section{Atmospheric Precipitation Phase Determination}

Most meteorological PPDS approaches are based on measured atmospheric conditions. There are many approaches that range from complex bulk microphysical schemes to simplified empirical approaches using thickness values or freezing levels to determine phase. 
Snow, wet snow, and/or rain might form when $T_{A G}$ decreases with height, while, a $T_{A G}$ profile consisting of a warm layer $\left(>0{ }^{\circ} \mathrm{C}\right)$ aloft and a cold layer below $\left(<0{ }^{\circ} \mathrm{C}\right)$ usually is needed to form ice pellets, supercooled rain, and freezing rain (Figure 4) [26].

\subsection{Bulk Microphysical Schemes}

Meteorological models commonly use bulk microphysical schemes to determine the hydrometeor phase as precipitation falls to the surface. These schemes assume a size distribution for hydrometeors [26]. A hydrometeor's size determines the amount of energy needed for phase change. Small hydrometeors changing phase faster than large hydrometeors is often the cause of mixed phase precipitation [26,29].

There are both sophisticated and simplified bulk microphysical schemes (Table 1). The sophisticated Purdue-Lin scheme incorporates six hydrometeor classes (water vapor, cloud water, cloud ice, rain, snow, and graupel) and mixed-phase processes [40]. This scheme applies complex equations to account for evaporation, sublimation, deposition, condensation, aggregation, accretion, Bergeron processes, freezing, and melting. Other bulk microphysical schemes are simpler, e.g., the WSM3 (WFR [Weather Research and Forecasting] Single Moment-3) with three precipitation phases [41] that does not allow mixed phase processes, assuming an instantaneous phase changes to occur at freezing levels.

Table 1. WRF Model Version 3 Microphysical Schemes from most to least complex table modified from [42].

\begin{tabular}{ccc}
\hline Microphysical Scheme & Precipitation Types & Allows Mixed Phase Processes \\
\hline Morrison 2-Moment & 10 & Yes \\
Thompson & 7 & Yes \\
Goddard & 6 & Yes \\
Purdue Lin & 6 & Yes \\
WSM6 & 6 & Yes \\
WSM5 & 5 & No \\
WSM3 & 3 & No \\
Kessler & 3 & No \\
Eta GCP & 2 & Yes \\
\hline
\end{tabular}

Of note, most microphysical schemes do not account for drizzle formed through the warm rain process in low clouds, usually under inversions. These clouds contain little ice condensation nuclei causing supercooled drizzle without the melting and refreezing layers in Figure 4 [1,33].

\subsection{Empirical Phase Determination Schemes}

\subsubsection{Thickness Values}

A thickness value is the difference in height $\left(D_{Z}\right)$ between two standard pressure levels (e.g., between 500 and $1000 \mathrm{mb})$ identified by Radiosonde data. $D_{Z}$ is proportional to the changes in pressure $\left(D_{P}\right)$ and density. Given a constant $D_{P}$, warm air is less dense resulting in a larger $D_{Z}$, while, cold air has the opposite properties (Figure 5). Critical thickness values e.g., $1300 \mathrm{~m}$ for 1000-850 mb, $2840 \mathrm{~m}$ for 1000-700 mb and $5400 \mathrm{~m}$ for $1000-500 \mathrm{mb}$ [43] can be used as rain/snow thresholds. Snow is expected when a $D_{Z}$ is 
lower than the critical $D z$ value, and rain if a $D z$ is higher. Meteorology traditionally used critical $D z$ values $[25,43]$ when less computational PPDS methods were necessary (Figure 5). The advantage of this method is its simplicity. It is less sensitive to diurnal change than $T_{A}$ but still has many of the same disadvantages. Specifically this method assumes a constant or average change in temperature with height (Figure 2A, Figure 5A,C) but cannot identify cold, warm, (Figure 2B,C and Figure 5B) or isothermal layers (Figure $3 \mathrm{~B}$ ) in the vertical temperature profile affecting precipitation phase [25].

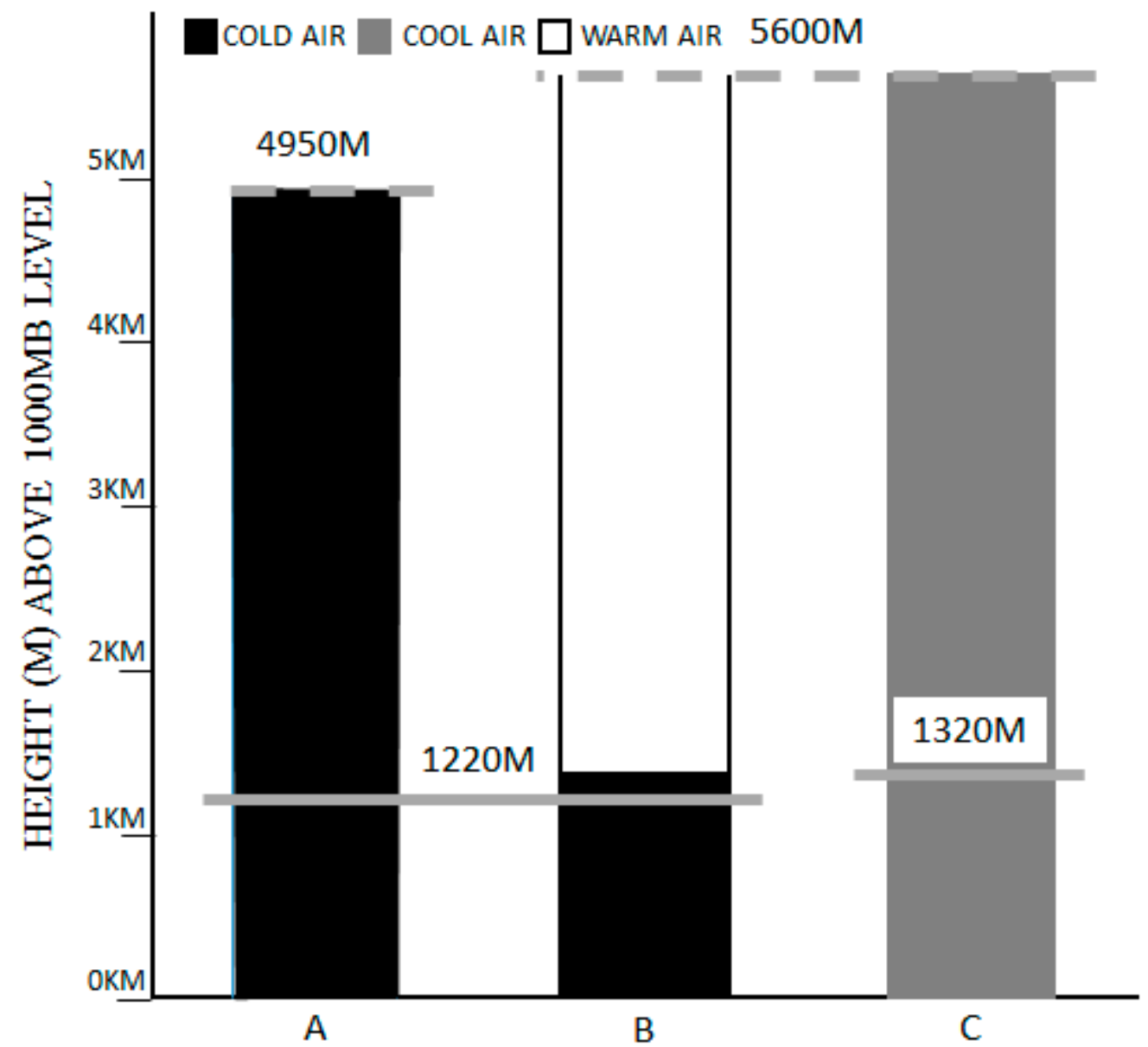

Figure 5. Example of thickness values $\left(D_{Z}\right)$ for 1000 to $850 \mathrm{mb}$ (solid line), and for 1000 to $500 \mathrm{mb}$ (hatched line) for air columns with (A) a cold air mass; (B) an air mass boundary and $(\mathbf{C})$ a warm air mass.

\subsubsection{Freezing Levels}

The height of $Z 0{ }^{\circ} \mathrm{C}$ is available from radiosonde data and is also used to determine the probability of snow falling through a near surface warm layer (Table 2). Similar approaches exist for above ground $T_{W}$ and $T_{D}$.

Table 2. Probability of snow based on the height of the freezing layer $\left(T_{A G}=0{ }^{\circ} \mathrm{C}\right)$.

\begin{tabular}{cccccc}
\hline Freezing Layer Height $(\mathbf{m}) *$ & $\mathbf{0}$ & $\mathbf{9 5}$ & $\mathbf{2 0 0}$ & $\mathbf{2 8 0}$ & $\mathbf{3 6 5}$ \\
\hline Snow Probability $(\%)$ & 100 & 90 & 70 & 50 & 0 \\
\hline$*$ Converted from feet $[44]$ to the nearest $5 \mathrm{~m}$.
\end{tabular}


On average, a warm layer must be at least $1200 \mathrm{ft}(365 \mathrm{~m})$ thick to completely melt all snow [43]. This approach does not account for the following factors affecting $D_{\text {melt }}$ : (a) Actual temperature and wind speed of the warm layer; (b) a possible second warm layer; or (c) snowfall intensity and flake size.

\section{Surface Based Precipitation Phase Determination}

Many hydrological models rely solely on automated observing sensors (AOS) for weather data. Most PPDS apply the same empirical formula to all precipitation events reviewed in [21]. Of note, one weakness for all surface based PPDS methods is that they are not physically sound, unable to account for microphysical processes occurring above the surface.

\subsection{Time Step Dependence}

Many PPDS schemes use average daily $T_{A}$ for a critical rain/snow threshold $\left(T_{R S}\right)$ or slight modifications of it. Ruddell et al. [45] and Schreider et al. [46] e.g., use daily minimum $T_{A}$. In 1956, the U.S. Army Corps of Engineers [23] determined, from hourly observations, that $T_{R S}$ was normally between $1.1{ }^{\circ} \mathrm{C}$ and $1.7{ }^{\circ} \mathrm{C}$ while Sælthun [47] found a larger $T_{R S}$ range $\left(-1{ }^{\circ} \mathrm{C}\right.$ to $\left.4{ }^{\circ} \mathrm{C}\right)$ using daily average $T_{A}$. Harder and Pomeroy [29] showed that a daily $T_{A}$ had double the temperature range with 5\% or more misclassified precipitation than an hourly time-step. A shorter time step decreases the uncertainty of actual temperature during precipitation caused by e.g., diurnal temperature change [30], and air mass boundaries [48]. However, reducing the time step further to $15 \mathrm{~min}$ gave similar misclassified precipitation as one hour [29].

\subsection{Regional Variance}

Some studies suggest that $T_{R S}$ may be dependent on local terrestrial properties. Yang et al. [49] and Dai [18] noted changes in $T_{R S}$ due to regional variations in $R H$, air salinity, and elevation. Using a global 3 hourly synoptic network, Dai [18] estimated the average $T_{R S}$ to be $1.2^{\circ} \mathrm{C}$ over land and $1.9^{\circ} \mathrm{C}$ over oceans. Similarly, Feiccabrino [19] found a $T_{R S}$ of $2.0{ }^{\circ} \mathrm{C}$ over the North Sea, $1.5{ }^{\circ} \mathrm{C}$ over the Scandinavian Mountains, and $1.0^{\circ} \mathrm{C}$ over most land. Motoyama [50] and Ólafsson and Haraldsdóttir [30] found greater $T_{R S}$ variance in their island studies $\left(0^{\circ} \mathrm{C}\right.$ to $\left.3{ }^{\circ} \mathrm{C}\right)$ than found in both broader, and inland studies. Also of note, Ólafsson and Haraldsdóttir, [30] and Kienzle [31] found similar seasonal oscillations for coastal, inland, and lee of mountain $T_{R S}$ Values.

\subsection{Variations Caused by Threshold Determination Method}

The differences in reported $T_{R S}$ values (Table 3) may partly be attributed to the way they have been determined. Feiccabrino et al. [21] and Ye et al. [1] compare measured (visual observation) and modeled precipitation phase, while many studies e.g., Wen et al. [2] compare modeled and measured snow depths. For the latter type, the representation of (a) wind correction of gauge catch; (b) spatial resolution of the watershed; (c) lapse rate; and (d) snow melt etc. in the model has an influence on the determined $T_{R S}$ value. 
Table 3. Examples of $T_{R S}$ values along with applied region and method used to determine the value. (M) Determined from modeled snow depths, SWE, or snow duration, (DO) determined from direct observation of precipitation phase, and (IO) determined indirectly from e.g., albedo variation.

\begin{tabular}{|c|c|c|c|}
\hline Model Name, Reference & $\boldsymbol{T}_{R S}{ }^{\circ} \mathrm{C}$ & Applied Region & $\begin{array}{c}T_{R S} \\
\text { Method } \\
\end{array}$ \\
\hline CLM Community Land Model [2] & 2.5 & French Alps & $\mathrm{M}$ \\
\hline $\begin{array}{l}\text { WRF_CLM Weather Research and Forecasting } \\
\text { CLM [2] }\end{array}$ & 2.5 & French Alps & M \\
\hline BATS Biosphere-Atmosphere Transfer Scheme [49] & 2.2 & Former Soviet Union & M \\
\hline Dai $[18]$ & $\begin{array}{l}1.9 \\
1.2\end{array}$ & $\begin{array}{l}\text { Ocean; world wide } \\
\text { Land; world wide }\end{array}$ & DO \\
\hline Feiccabrino et al. [21] & 1.0 & Sweden & DO \\
\hline Feiccabrino et al. $[48]$ & 1.0 & Northern US & DO \\
\hline L’hôte et al. [51] & $0.75-1.25$ & Andes & $\mathrm{IO}$ \\
\hline L'hôte et al. [51] & $0.50-1.00$ & Switzerland & DO \\
\hline Ye et al. [1] & $0.5-1.0$ & European Russia & DO \\
\hline Ye et al. [1] & $1.5-2.5$ & South-central Siberia & DO \\
\hline $\begin{array}{c}\text { HBV } \\
\text { Braun and Lang [52] } \\
\text { Hottelet } \text { et al. }[53]\end{array}$ & $\begin{array}{c}0.5 \\
-0.8,1.0\end{array}$ & $\begin{array}{l}\text { Switzerland, low Alpine } \\
\text { Czech Republic, } \\
\text { sub-alpine }\end{array}$ & $\begin{array}{l}M \\
M\end{array}$ \\
\hline $\begin{array}{c}\text { EALCO Ecological Assimilation of Land and Climate } \\
\text { Observations [54] }\end{array}$ & 0.0 & Northern Canada & M \\
\hline $\begin{array}{l}\text { ISBA Interactions between Soil, Biosphere and } \\
\text { Atmosphere [55] }\end{array}$ & -1.5 & $\begin{array}{l}\text { Tropical Andes } \\
\text { Cordillera, }\end{array}$ & M \\
\hline
\end{tabular}

\subsection{Air Temperature Threshold Schemes}

\subsubsection{Critical Air Temperature Threshold Schemes}

A $T_{R S}$ is defined as the $T_{A}$ at which the likelihood of snow equals the likelihood of rain $[24,30]$. Precipitation is assumed to fall as snow (rain) if the temperature is cooler (warmer) than $T_{R S}$ [2].

Despite knowledge of regional and seasonal variance, many models use a fixed $T_{R S}$. However, some models e.g., the CHRM and the United States National Weather Service (NWS) snow accumulation and ablation models, have a default $T_{R S}$ that can be changed either for single events or be permanently adjusted [56,57].

The main advantage with $T_{R S}$ is that it is a quick simple method using minimal processing power, and the required parameters are widely available while other options may not be e.g., [24]. The main disadvantage is that it does not take into account mixed phase precipitation that often occurs when $T_{A}$ approach $T_{R S}$. Daly et al. [58] concluded that using a $T_{R S}$ was the main weakness in their study resulting in a lower than observed snow water equivalent by a systematic underestimation of the snow fraction $(S F)$. 


\subsubsection{Dual Air Temperature Threshold Schemes}

To account for the gradual decrease in $S F$ occurring as $T_{A}$ approaches $T_{R S}$, some models use a dual threshold method whereby all precipitation colder than a snow temperature threshold $\left(T_{S}\right)$ is modeled as snow and warmer than a rain temperature threshold $\left(T_{R}\right)$ is modeled as rain. The precipitation phase transition zone between $T_{S}$ and $T_{R}$ is considered mixed and proportional to a linear or curvelinear relationship between the defined thresholds [29]. Some examples of models using linear dual threshold methods are: Community Atmospheric Model (CAM) Version 3.0 with $T_{S}-5{ }^{\circ} \mathrm{C}$ and $T_{R} 0{ }^{\circ} \mathrm{C}$, The University of British Columbia (UBC) Watershed Model [31] with $T_{S} 0.6{ }^{\circ} \mathrm{C}$ and $T_{R} 3.6{ }^{\circ} \mathrm{C}$. Curvelinear examples are: WATCLASS 2.7 [34], and CLASS 3.1 [4] with $T_{S} 0.45{ }^{\circ} \mathrm{C}$ and $T_{R} 5.97{ }^{\circ} \mathrm{C}$ based on the Auer [59] polynomial.

The dual threshold methods have been found to result in less misclassified precipitation than $T_{R S}$ in many comparison studies e.g., [2,21]. Of the dual threshold methods, the approach applying a linear decrease in $S F$ requires the least processing power. However, a linear decrease in $S F$ should theoretically have more misclassified precipitation than a curvelinear $T_{A}-S F$ relationship [21].

All methods below will require additional processing power and might require variables not already found in a hydrological model.

\subsubsection{Air Mass Boundary Scheme}

Air mass boundaries which are known to change lower atmospheric conditions (Figure 2B,C) cannot be measured by AOS, but can be identified at the surface through temperature and wind changes when past, current, and future surface weather observations are compared [60-64]. Cold air mass boundaries were found to have $T_{S}$ and $T_{R}$ values $1{ }^{\circ} \mathrm{C}$ warmer than all other precipitation observations [48]. When treated separately, total misclassified precipitation was reduced from $7.0 \%$ to $5.4 \%$ for the temperature range $-1{ }^{\circ} \mathrm{C}$ to $5^{\circ} \mathrm{C}[48]$.

\subsection{Temperature Schemes Including Humidity}

PPDS can be based on different types of surface temperature. $T_{A}$ methods do not include humidity, the second-most significant factor in determining precipitation type [27,29,33]. Some researchers have found $T_{D}$ [20], $T_{W}$ [27], and a combination of $R H$ and $T_{A}$ [1] to be better predictors of the precipitation phase. However, the assumption that surface humidity is fully representative of the atmospheric humidity is incorrect. It is crucial to remember that the atmosphere above the surface through which a hydrometeor falls is a major factor in melting and refreezing.

\subsubsection{Dew Point Temperature Schemes}

A $T_{D}$ is the surface air temperature an air parcel would have to be cooled to in order to reach saturation at a constant pressure without moisture exchange [20]. Saturation temperatures differ between ice and water, therefore, requiring different formulas for $T_{D}$ [29].

In near-saturated mountain environments, $T_{A} \approx T_{D} \approx T_{W}$ and $T_{D}$ was found to be more reliable for phase determination than $T_{A}$ [20]. Marks et al. [20] hypothesized that in this moist environment, $T_{D}$ was a proxy for hydrometeor temperature and would therefore identify the liquid or solid phase. Concerning 
this environment, a $T_{R S}>0{ }^{\circ} \mathrm{C}$ was found to misclassify more rain as snow than a threshold of $T_{D}=0{ }^{\circ} \mathrm{C}$. Notably, this method did not work well when there was warm air aloft or when cloud bases were well above the surface [20].

$T_{D}$ thresholds were found to have less spatial variations than $T_{R S}[1,21]$. No overall seasonal changes in $T_{D}$ thresholds were found [1]. The $T_{D}$ method can be easily applied when data is supplied by an AOS. However, knowledge of which relationship used by the AOS to derive $T_{D}$ may be necessary.

\subsubsection{Wet-Bulb Temperature Schemes}

The $T_{W}$ is the temperature an air parcel would be cooled to by evaporation until saturation without exchange of sensible heat [20]. A $T_{W}$ scheme approximates the effect of sublimation and evaporation on snowflakes in air warmer and drier than the cloud in which it was formed [20,33]. $T_{W}$ is derived from $T_{A}, T_{D}$, air pressure, and saturation vapor pressure. Snowfall frequently occurs when $T_{A}>0{ }^{\circ} \mathrm{C}$ and the near surface $R H$ is $<100 \%$, such that $T_{A}>T_{W}>T_{D}$ [20]. Under these unsaturated (drier) conditions, $T_{W}$ may be more effective than $T_{D}$ in a PPDS [20].

\subsubsection{Relative Humidity Schemes}

There are several studies showing that transition from rain to snow seems to take place at warmer temperatures for dry than for moist air [1,25,27,29,33,50]. Matsuo et al. [27] compared observed phase with surface $T_{A}$ and $\mathrm{RH}$ in Japan to find snow and rain $R H$ thresholds. All precipitation occurring for conditions plotted below the snow $R H$ threshold were assumed snow, and above the rain $R H$ threshold were assumed rain. Precipitation between the two $R H$ thresholds was considered mixed. They found slightly varying relationships for different locations, but for each $10 \%$ drop in $\mathrm{RH}$ the $T_{R S}$ would increase by about $1{ }^{\circ} \mathrm{C}$ (Figure 6A,B).

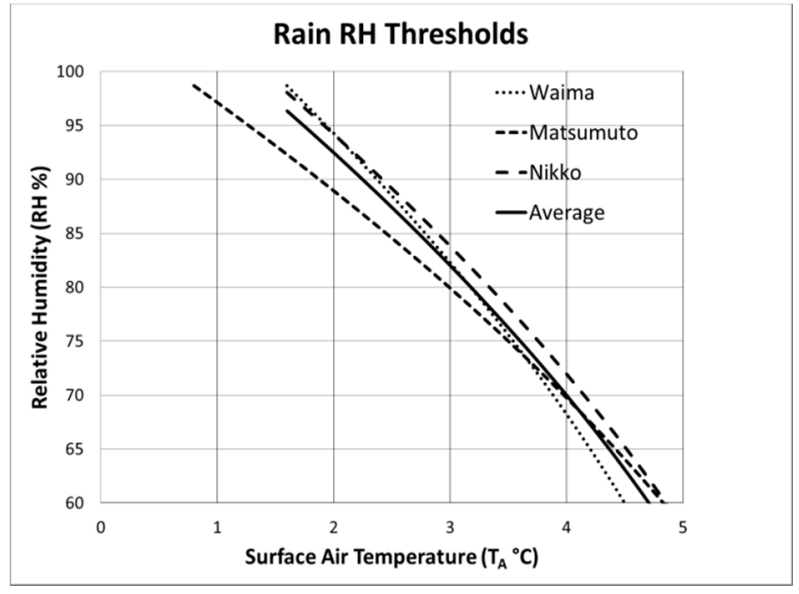

(A)

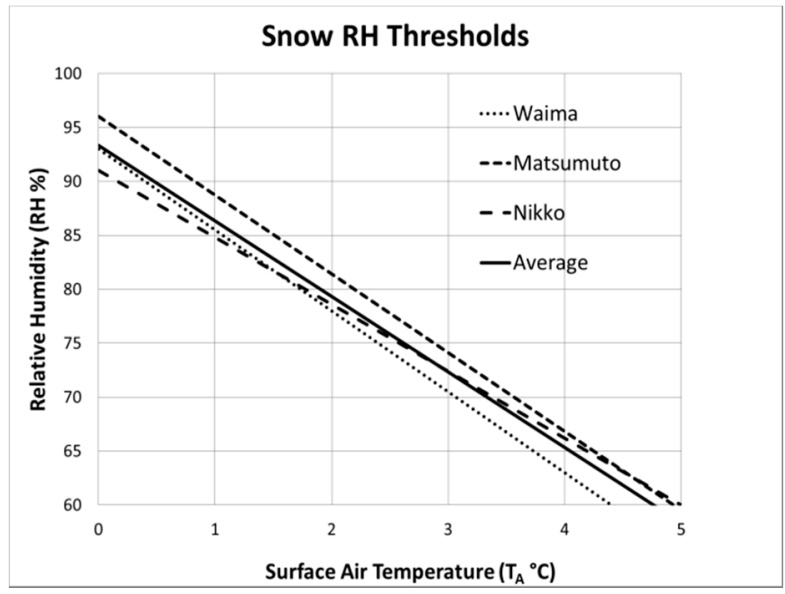

(B)

Figure 6. Rain (A) and snow (B) thresholds as a function of RH determined from equations in [27].

Similar trends were observed in Gjertsen and Ødegaard's [33] study, where the probability of snow for a given $T_{A}$ is increased with decreasing $R H$ (Figure 7). 
Harder and Pomeroy [29] utilized knowledge from research on sublimation of blowing snow to estimate a hydrometeor temperature (Ti) including the effects of $R H$. This $T i$, achieved by an iterative process, was shown to be a better indicator of precipitation phase than $T_{R S}$. They used energy and mass balances of a sublimating ice sphere and assumed that the inner temperature of the ice sphere was the same as its surface temperature. They also assumed that the Nusselt and Sherwood numbers, indexes for the degree of turbulent transfer from a particle surface to the atmosphere of energy and water vapor respectively, were equal. Hydrometeor temperatures, calculated for different $R H$-values, using their relationships for the most interesting $T_{A}$ range $\left(-5{ }^{\circ} \mathrm{C}\right.$ to $\left.+5{ }^{\circ} \mathrm{C}\right)$ are shown in Figure 8 , and confirm that $T i$ increases with $R H$.

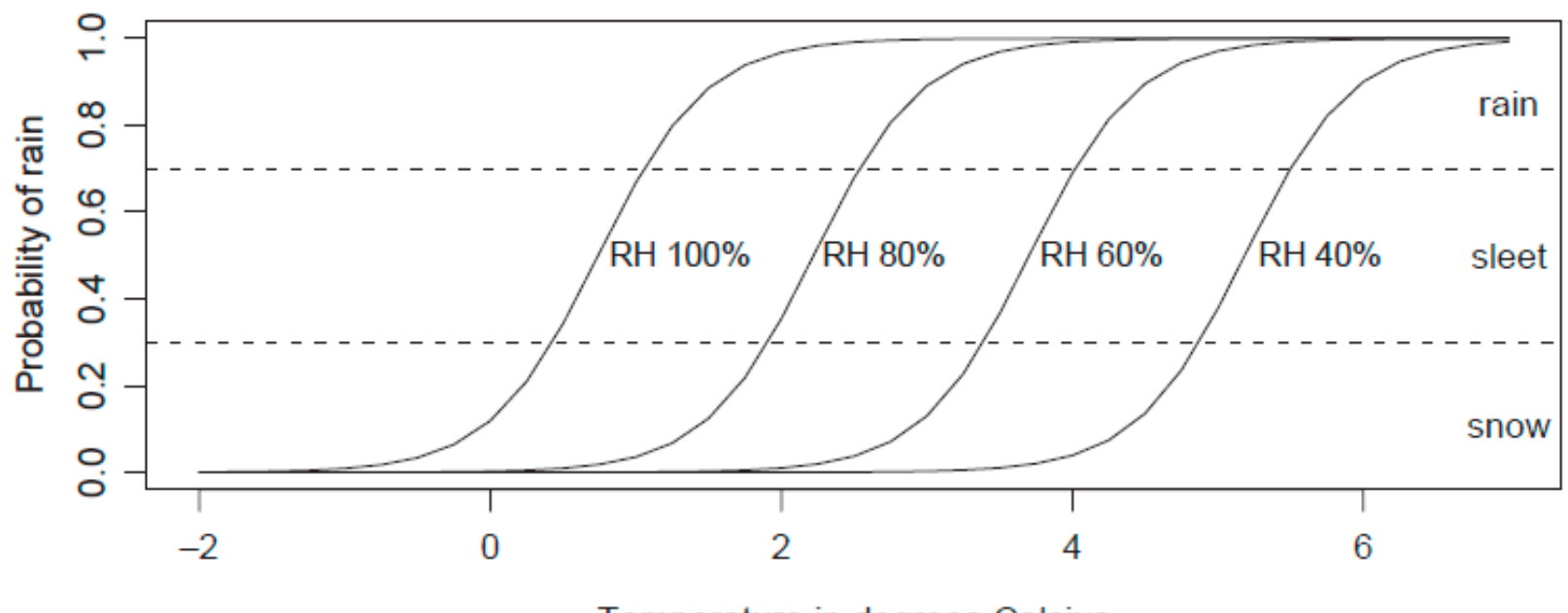

Temperature in degrees Celsius

Figure 7. Probability of rain versus surface air temperature for different $R H$ (Figure 7 reprinted from Gjertsen and Ødegaard [33], with permission from Elsevier).

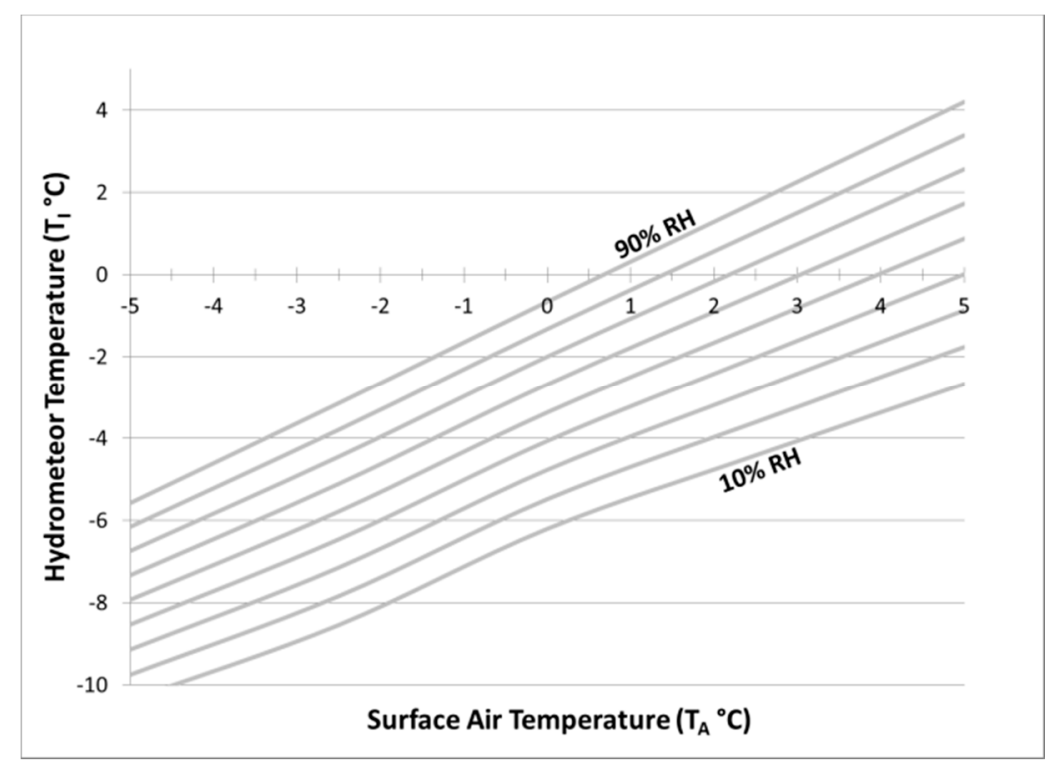

Figure 8. Ti versus $\mathrm{T}_{\mathrm{A}}$ with $R H$ varying from $90 \%$ (top curve) to $10 \%$ (base curve).

An $80 \%$ increase in $R H$ gives a $T i$ increase of $\approx 4.5{ }^{\circ} \mathrm{C}$ for $T_{A} \approx-5{ }^{\circ} \mathrm{C}$ and $\approx 6.5{ }^{\circ} \mathrm{C}$ for $T_{A} \approx+5{ }^{\circ} \mathrm{C}$ (Figure 8). The average $T i$ thus increases about $0.7{ }^{\circ} \mathrm{C}$ per $10 \%$ rise in $R H$ in the relevant $T_{A}$ range -5 to 
$+5{ }^{\circ} \mathrm{C}$. The hydrometeor rain/snow threshold temperature $T i=0{ }^{\circ} \mathrm{C}$, from now on denoted $T_{R H}$, thus occurs at $0.7{ }^{\circ} \mathrm{C}$ warmer $T_{A}$ for each $10 \%$ drop in $R H$ (Figures 8 and 9). This agrees well with other reported $T_{\mathrm{RH}}$ relationships with about $0.85{ }^{\circ} \mathrm{C}$ warmer $T_{A}$ for each $10 \% R H$ drop (Figure 9). The $T_{R H}$ values from Gjertsen and Ødegaard [33], were determined by setting $T_{R H}$ as the temperature having $50 \%$ $S F$ and for Matsuo et al. [27] as the average of the reported rain and snow humidity thresholds (Figure 6A,B).

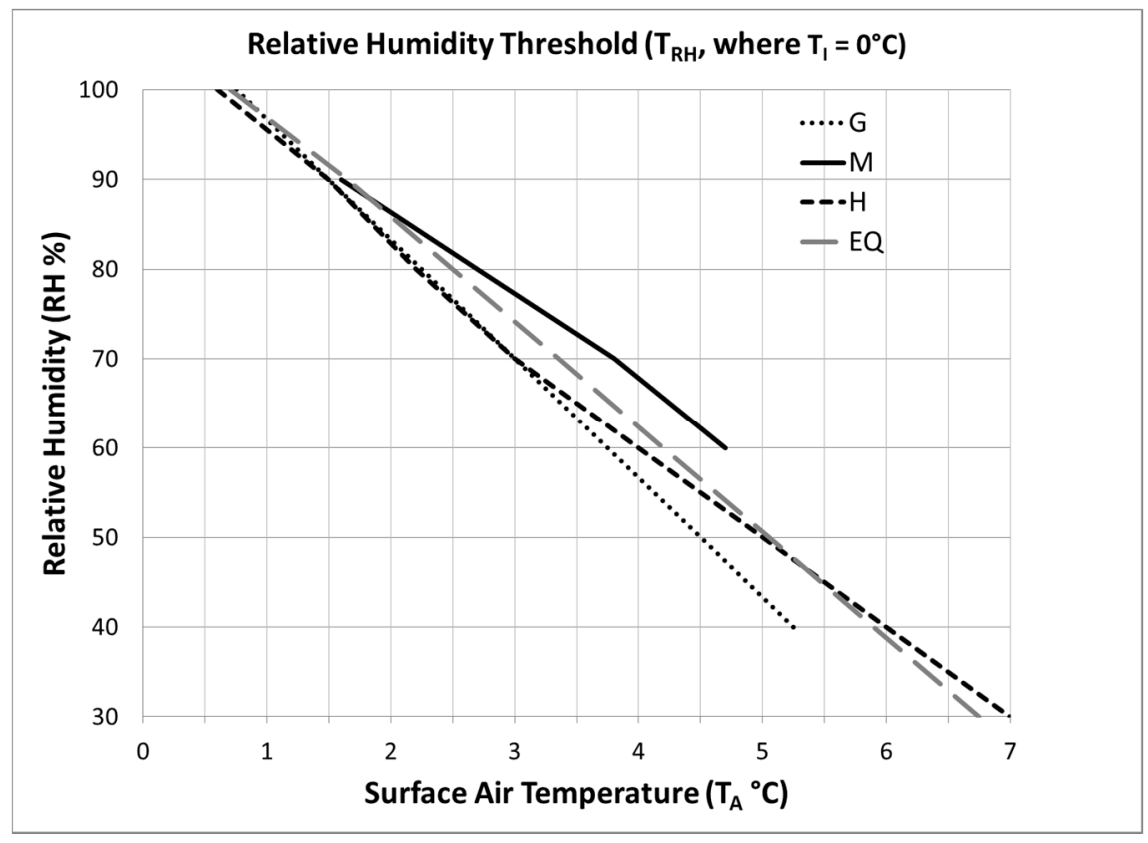

Figure 9. $T_{\mathrm{RH}}$ Relationship where $T_{\mathrm{I}}=0{ }^{\circ} \mathrm{C}$ for a given $T_{A}$, and $R H$ from studies; $\mathrm{G}=$ Gjertsen and Ødegaard [33], $\mathrm{M}=$ Matsuo et al. [27], $\mathrm{H}=$ Harder and Pomeroy [29], and $\mathrm{EQ}=$ Determined by Equation (1).

Since the $T_{\mathrm{RH}}$ relationships for $T_{A}$, and $R H$ from all three studies show similar almost linear relationships (Figure 9) having about $0.85{ }^{\circ} \mathrm{C}$ warmer $T_{A}$ per $10 \% R H$ decrease, the following simple relationship (for $T_{\mathrm{RH}}$ between $0{ }^{\circ} \mathrm{C}$ and $5{ }^{\circ} \mathrm{C}$ ) is suggested;

$$
\mathrm{T}_{\mathrm{RH}}=0.75+0.085 \times(100-\mathrm{RH})
$$

This very simple equation gives $T_{R S}(40 \%)=4.9^{\circ} \mathrm{C}$ and $T_{R S}(90 \%)=1.65{ }^{\circ} \mathrm{C}$, thus similar results as Matsuo et al. [27], Gjertsen and Ødegaard [33], and Harder and Pomeroy [29] (Figure 9). However, a weakness with $R H$-based methods is that $R H$ is very sensitive to small errors in $T_{A}$, e.g., a $0.2{ }^{\circ} \mathrm{C}$ error leads to an $R H$ error of $4 \%$ at $T_{A}=0{ }^{\circ} \mathrm{C}$ [65]. Accurate measurements of $T_{A}$ are thus needed.

\section{Summary}

The goal here was to increase basic meteorological knowledge of precipitation phase change processes and to point out or identify techniques to improve surface based PPDS. Most hydrological models use daily average surface temperature based empirical formulas to imply precipitation phase without regard for atmospheric processes. These methods like all other surface based methods do not 
account for variations in atmospheric conditions that cause actual vertical temperature profiles to be uniquely modified by e.g., melting and refreezing.

However, methods developed or modified through knowledge of lower atmospheric interactions between air and hydrometers e.g., relative humidity, air mass boundaries, or precipitation intensity, should allow for statistically better chances of correct precipitation phase determination in surface based models. As a bonus, some of the below methods can be implemented without much difficulty since they only need AOS data already available in hydrological modeling.

Surface based precipitation phase determination methods can be improved by:

- Using a shorter a time-step:

Harder and Pomeroy [29], showed that by decreasing the time step from one day to one hour resulted in more than a $50 \%$ decrease in the temperature range for which mixed-phase (rain and/or snow) precipitation occurred.

This was most likely caused by many precipitation events occurring on a sub-daily timescale (most common exception warm frontal light stratiform precipitation) which often ranges from tens of minutes (intense cumuliform precipitation) to several hours in duration [48]. Since temperatures change diurnally with a maximum temperature in the afternoon and a minimum temperature in the morning, a decrease in the temperature sampling time step closer to the time scale to which precipitation events occur would result in a more representative temperature for precipitation phase determination.

- Introducing single (or dual rain/snow) thresholds which vary with relative humidity $R H(\%)$ :

Matsuo et al. [27], Gjertsen and Ødegaard [33], and Harder and Pomeroy [29] all show that $T_{R S}$ increases with decreasing $R H$. Based on these studies, it is shown that, for the surface air temperature range of $0{ }^{\circ} \mathrm{C}$ to $5{ }^{\circ} \mathrm{C}, T_{R H}$ could be approximated by $0.75+0.085 \times(100-\mathrm{RH})$.

- Identification of air mass boundaries:

Feiccabrino et al. [48] found $T_{S}$ and $T_{R}$ values for a group of cold air mass boundaries to be $1{ }^{\circ} \mathrm{C}$ warmer than that of all other observations. When these observation groups were analyzed separately, total misclassified precipitation was reduced by $23 \%$ in the temperature range -1 to $5{ }^{\circ} \mathrm{C}$.

This was thought to be the cause of warm air rising over a lower denser cold air mass for most precipitation events with the main exception being cold fronts having precipitation occur ahead of the front in a single air mass. This theory worked in a Central United States continental climate [48] but did not improve precipitation phase identification in the maritime mountain environment of the Scandinavian Peninsula [19]. In a maritime or island environment surface air in the winter is modified by the warm ocean temperatures making all but the strongest frontal passages advect warm air over the land. This ocean affect could be the reason for such different results between studies.

- Inclusion of precipitation intensity and/or duration:

No direct study available for confirmation, but Harder and Pomeroy [29] noted that the temperature range between $T_{S}$ and $T_{R}$ narrowed for heavy precipitation events and Minder et al. [17] showed an increase in the isothermal layer depth associated with melting precipitation. The presence of unstable air under the isothermal layer should allow for snow reaching the ground at warmer air temperatures similar to ocean effects from Ólafsson and Haraldsdóttir [30]. 
The lack of a study in this area would suggest that either negative results were found and therefore not published, or it has not been looked into. Considering that most studies are carried out using a daily or hourly precipitation and temperature time-step, it is possible that cooling of the temperature due to melting and sublimation occurred rapidly enough to keep warm high intensity snow events from being observed often enough to be a notable issue. The isothermal layer can thicken for long duration events (Section 2.2.3), but the surface temperature can also lower with sublimation, evaporation, or, to a lesser extent, modify to being closer to the precipitation temperature.

- Seasonal and/or terrain dependent lapse rates:

Dai [18] reported a warm bias $\left(+0.7^{\circ} \mathrm{C}\right)$ for $T_{R S}$ over oceans compared to over land. This phenomena was confirmed in two other studies [19,30], and is thought to be caused by the ocean heating the near surface atmosphere resulting in higher lapse rates over the coast and water.

It is therefore suggested and shown [19] that different snow/rain temperature threshold values should be used for different geographic landscapes. This is due to ocean/water heating the near surface air causing the snow/rain threshold to be warmer over open water than land. The rain/snow threshold differences on land could be caused by terrain effects on cloud formation and precipitation intensity.

This paper was directed mostly towards techniques to improve point precipitation phase identification for possible quality assurance checks, reanalysis of historical data, or the assigning of a precipitation phase when there is no manual observation or automated device present to report a phase. Many of the automated methods/instruments that report precipitation phase use; (1) Doppler radar; (2) optical sensors [66]; (3) hotplates [67] or (4) two dimensional video distrometers (2DVD) [68]. However, they have often been put into operation without an in-depth intercomparison which brings into question the quality, consistency, compatibility, and representativeness of their data [66]. In response to this, the WMO (World Meteorological Organization) Solid Precipitation InterComparison (WMO-SPICE) study was created. The initial WMO-SPICE findings are just now becoming available e.g., [69,70].

It is also beyond the scope of this paper, however of great value to understand how landscapes such as forest or open fields affect the spatial distribution of snowfall, see e.g., [71].

\section{Conclusions}

Fixed rain/snow thresholds in surface based models tend to integrate average atmospheric conditions that control phase change when distinction could be useful. Distinct Atmospheric conditions and terrain features which cause warmer than normal rain/snow temperature thresholds are:

- Cold frontal passage

- Locations over or near large ice free water bodies

- Low relative humidity

- Long duration or high intensity precipitation events

- Locations on the windward side of mountains (caused by increased precipitation intensity)

The above surface and atmospheric weather conditions could all be identified using surface observations while the above terrain features that interact with lower atmospheric conditions can be easily identified on topographic maps. This information is readily available and should therefore be used to improve precipitation phase determination in surface based models. 


\section{Author Contributions}

William Graff and James Feiccabrino co-wrote Sections 2 and 3 and performed general draft preparation. Nils Sandstrum contributed radar information and proof reading. Angela Lundberg contributed most of Section 4.5.3, Equation (1) and Figures 6, 8 and 9. David Gustafsson, Angela Lundberg and James Feiccabrino co-wrote Sections 1, 4, and 5. James Feiccabrino constructed Figures 1-5, collected contributions from co-authors and prepared the manuscript.

\section{Conflict of Interest}

The authors declare no conflict of interest.
Abbreviations

$\begin{array}{cc}\text { PPDS } & \text { precipitation phase determination scheme } \\ \text { AOS } & \text { automated observing system } \\ \text { Dmelt. } & \text { depth of the near-freezing isothermal layer (in the atmosphere) } \\ D_{P} & \text { difference in (atmospheric) pressure } \\ D_{Z} & \text { difference in (atmospheric) height } \\ R H & \text { surface relative humidity } \\ S F & \text { snow fraction } \\ T_{A} & \text { surface air temperature } \\ T_{A G} & \text { above ground air temperature } \\ T_{D} & \text { surface dew point temperature } \\ T_{i} & \text { hydrometeor temperature } \\ T_{R} & \text { rain temperature threshold (all precipitation warmer is rain) } \\ T_{R S} & \text { single rain/snow threshold temperature } \\ T_{S} & \text { snow temperature threshold (all precipitation colder is snow) } \\ T_{W} & \text { surface wet bulb temperature } \\ Z_{S} & \text { snow elevation (lowest at which snow falls) } \\ Z 0^{\circ} \mathrm{C} & \text { height of the } 0{ }^{\circ} \mathrm{C} \text { isotherm }\end{array}$

\section{References}

1. Ye, H.; Cohen, J.; Rawlins, M. Discrimination of solid from liquid precipitation over northern Eurasia using surface atmospheric conditions. J. Hydrometeorol. 2013, 14, 1345-1355.

2. Wen, L.; Nagabhatla, N.; Lü, S.; Wang, S.Y. Impact of rain snow threshold temperature on snow depth simulation in land surface and regional atmospheric models. Adv. Atmos. Sci. 2013, 30, 1449-1460.

3. Thériault, J.M.; Rasmussen, R.; Ikeda, K.; Landolt, S. Dependence of snow gauge collection efficiency on snowflake characteristics. J. Appl. Meteorol. Climatol. 2012, 51, 745-762.

4. Bartlett, P.A.; MacKay, M.D.; Verseghy, D.L. Modified snow algorithms in the Canadian land surface scheme: Model runs and sensitivity analysis at three Boreal forest stands. Atmos. Ocean 2006, 43, 207-222.

5. Coudrain, A.; Francou, B.; Kundzewicz, Z.W. Glacier shrinkage in the Andes and consequences for water resources—Editorial. Hydrol. Sci. J. 2005, 50, 925-932. 
6. Lundberg, A.; Fieccabrino, J. Sea ice growth, modeling of precipitation phase. In Proceedings of the 20th International Conference on Port and Ocean Engineering under Arctic Conditions, Lulea, Sweden, 9-12 June 2009.

7. Davis, R.E.; Lowit, M.B.; Knappenberger, P.C.; Legates, D.R. A climatology of snowfall-temperature relationships in Canada. J. Geophys. Res. Atmos. 1999, 104, 11985-11994.

8. Bellaire, S.; Jamieson, B. Forecasting the formation of critical snow layers using a coupled snow cover and weather model. Cold Reg. Sci. Technol. 2013, 94, 37-44.

9. Lundberg, A.; Nakai, Y.; Thunehed, H.; Halldin, S. Snow accumulation in forests from ground and remote-sensing data. Hydrol. Process. 2004, 18, 1941-1955.

10. Lundberg, A.; Feiccabrino, J.; Westerlund, C.; Al-Ansari, N. Urban snow deposits versus snow cooling plants in northern Sweden: A quantitative analysis of snow melt pollutant releases. Water Qual. Res. J. Can. 2014, 49, 32-42.

11. Stewart, T.R.; Pielke, R., Jr.; Nath, R. Understanding user decision making and the value of improved precipitation forecasts lessons from a case study. Bull. Am. Meteorol. Soc. 2004, 85, 223-235.

12. Gray, D.M.; Toth, B.; Zhao, L.; Pomeroy, J.W.; Granger, R.J. Estimating areal snowmelt infiltration into frozen soils. Hydrol. Process. 2001, 15, 3095-3111.

13. Ecke, F.; Christensen, P.; Rentz, R.; Nilsson, M.; Sandström, P.; Hörnfeldt, B. Landscape structure and the long-term decline of cyclic grey-sided voles in Fennoscandia. Landsc. Ecol. 2010, 25, 551-560.

14. Braun, L.N. Modeling of the snow-water equivalent in the mountain environment. In Snow in Hydrology and Forests in High Alpine Areas; Bergmann, H., Lang, H., Frey, W., Issler, D., Salm, B., Eds.; IAHS Press: Wallingford, UK, 1991; pp. 3-17.

15. Sivapalan, M.; Takeuchi, K.; Franks, S.W.; Gupta, V.K.; Karambiri, H.; Lakshmi, V.; Liang, X.; McDonnell, J.J.; Mendiondo, E.M.; O’Connell, P.E.; et al. IAHS decade on Predictions in Ungauged Basins (PUB), 2003-2012: Shaping an exciting future for the hydrological sciences. Hydrol. Sci. J. 2003, 48, 857-880.

16. Fang, X.; Pomeroy, J.W.; Ellis, C.R.; MacDonald, M.K.; DeBeer, C.M.; Brown, T. Multi-variable evaluation of hydrological model predictions for a headwater basin in the Canadian Rocky Mountains. Hydrol. Earth Syst. Sci. 2013, 17, 1635-1659.

17. Minder, J.R.; Durran, D.R.; Roe, G.H. Mesoscale controls on the mountainside snow line. J. Atmos. Sci. 2011, 68, 2107-2127.

18. Dai, A. Temperature and pressure dependence of the rain-snow phase transition over land and ocean. Geophys. Res. Lett. 2008, doi:10.1029/2008GL033295.

19. Feiccabrino, J. A cross sectional study of rain/snow threshold changes from the North Sea across the Scandinavian Mountains to the Bay of Bothnia. In Proceedings of the 20th International Northern Research Basins Symposium and Workshop, Kuusamo, Finland, 16-21 August 2015; pp. 4-13.

20. Marks, D.; Winstral, A.; Reba, M.; Pomeroy, J.; Kumar, M. An evaluation of methods for determining during-storm precipitation phase and the rain/snow transition elevation at the surface in a mountain basin. Adv. Water Resour. 2013, 55, 98-110.

21. Feiccabrino, J.; Gustafsson, D.; Lundberg, A. Surface-based precipitation phase determination methods in hydrological models. Hydrol. Res. 2013, 44, 44-57. 
22. Kongoli, C.E.; Bland, W.L. Long-term snow depth simulations using a modified atmosphere-land exchange model. Agric. For. Meteorol. 2000, 104, 273-287.

23. United States Army Corps of Engineers (USACE). Snow Hydrology: Summary Report of the Snow Investigations; United States Army Corps of Engineers North Pacific Division: Portland, OR, USA, 1956; p. 437.

24. Kane, D.L.; Stuefer, S. Reflecting on the status of precipitation data collection in Alaska: A case study. Hydrol. Res. 2015, 46, 478-493.

25. Stewart, R.E. Precipitation types in the transition region of winter storms. Bull. Am. Meteorol. Soc. 1992, 73, 287-296.

26. Thériault, J.M.; Stewart, R.E. A parameterization of the microphysical processes forming many types of winter precipitation. J. Atmos. Sci. 2010, 67, 1492-1508.

27. Matsuo, T.; Sato, Y.; Sasyo, Y. Relationship between types of precipitation on the ground and surface meteorological elements. J. Meteorol. Soc. Jpn. 1981, 59, 462-475.

28. Lundquist, J.D.; Neiman, P.J.; Martner, B.; White, A.B.; Gottas, J.D.; Ralph, F.M. Rain versus snow in the Sierra Nevada, California: Comparing Doppler profiling radar and surface observations of melting level. J. Hydrometeorol. 2008, 9, 194-211.

29. Harder, P.; Pomeroy, J. Estimating precipitation phase using a psychrometric energy balance method. Hydrol. Process. 2013, 27, 1901-1914.

30. Ólafsson, H.; Haraldsdóttir, S.H. Diurnal, seasonal, and geographical variability of air temperature limits of snow and rain. In Proceedings of the International Conference on Alpine Meteorology (ICAM 2003), Brig, Switzerland, 19-23 May 2003; pp. 473-476.

31. Kienzle, S.W. A new temperature based method to separate rain and snow. Hydrol. Process. 2008, 22, 5067-5085.

32. Fassnacht, S.R.; Kouwen, N.; Soulis, E.D. Surface temperature adjustments to improve weather radar representation of multi-temporal winter precipitation accumulations. J. Hydrol. 2001, 253, $148-168$.

33. Gjertsen, U.; Ødegaard, V. The water phase of precipitation-A comparison between observed, estimated and predicted values. Atmos. Res. 2005, 77, 218-231.

34. Davison, B. Snow Accumulation in a Distributed Hydrological Model. Ph.D. Thesis, University of Waterloo, Waterloo, ON, Canada, 2003.

35. NOAA National Weather Service Radiosonde Observations. Available online: http://www.ua.nws.noaa.gov/factsheet.htm (accessed on 23 September 2015).

36. Kain, J.S.; Goss, S.M.; Baldwin, M.E. The melting effect as a factor in precipitation-type forecasting. Weather Forecast 2000, 15, 700-714.

37. Fujibe, $\mathrm{F}$. On the near- $0{ }^{\circ} \mathrm{C}$ frequency maximum in surface air temperature under precipitation: A statistical evidence for the melting effect. J. Meteorol. Soc. Jpn. 2001, 79, 731-739.

38. Lackmann, G.M.; Keeter, K.; Lee, L.G.; Ek, M.B. Model representation of freezing and melting precipitation: Implications for winter weather forecasting. Weather Forecast 2002, 17, 1016-1033.

39. Mitra, S.K.; Vohl, O.; Ahr, M.; Pruppacher, H.R. A wind tunnel and theoretical study of the melting behavior of atmospheric ice particles IV: Experiment and theory for snowflakes. J. Atmos. Sci. 1990, 47, 584-591. 
40. Chen, S.H.; Sun, W.Y. A one-dimensional time dependent cloud model. J. Meteorol. Soc. Jpn. 2002, 80, 99-118.

41. Hong, S.Y.; Lim, J.O.J. The WRF single-moment 6-class microphysics scheme (WSM6). J. Korean Meteorol. Soc. 2006, 42, 129-151.

42. Skamarock, W.C.; Klemp, J.B.; Dudhia, J.; Gill, D.O.; Barker, D.M.; Duda, M.G.; Huang, X.Y.; Wang, W.; Powers, J.G. A Description of the Advanced Research WRF Version 3; NCAR Tech. Note. NCAR/TN-475+ STR; National Center for Atmospheric Research: Boulder, CO, USA, 2008.

43. Venne, M.G.; Jasperson, W.H.; Venne, D.E. Difficult Weather: A Review of Thunderstorms, Fog, and Stratus, and Winter Precipitation Forecasting; AIRFM Command Tech. Report \#A246633; Augsburg Coll Minneapolis MN Center for Atmospheric and Space Sciences: Minneapolis, MN, USA, 1997.

44. McNulty, R.P. Winter Precipitation Type; NWS Central Region Tech. Attach. 88-4; National Weather Service: Kansas City, MO, USA 1988.

45. Ruddell, A.R.; Budd, W.F.; Smith, I.N.; Keage, P.L.; Jones, R. The South East Australian Alpine Climate Study: A report by the Meteorology Department, University of Melbourne, for the Alpine Resorts Commissions; Department of Meteorology, University of Melbourne: Melbourne, Australia, 1990; pp. 115.

46. Schreider, S.Y.; Whetton, P.H.; Jakeman, A.J.; Pittock, A.B. Runoff modelling for snow-affected catchments in the Australian alpine region, eastern Victoria. J. Hydrol. 1997, 200, 1-23.

47. Sælthun, N.R. "The Nordic" HBV Model, Description and Documentation of the Model Version Developed for the Project 'Climate Change and Energy Production'; Norwegian Water Resources and Energy Administration (NVE): Oslo, Norway, 1996.

48. Feiccabrino, J.; Lundberg, A.; Gustafsson, D. Improving surface-based precipitation phase determination through air mass boundary identification. Hydrol. Res. 2012, 43, 179-191.

49. Yang, Z.L.; Dickinson, R.E.; Robock, A.; Vinnikov, K.Y. Validation of the snow submodel of the biosphere-atmosphere transfer scheme with Russian snow cover and meteorological observational data. J. Clim. 1997, 10, 353-373.

50. Motoyama, H. Simulation of seasonal snowcover based on air temperature and precipitation. J. Appl. Meteorol. 1990, 29, 1104-1110.

51. L'hôte, Y.; Chevallier, P.; Coudrain, A.; Lejeune, Y.; Etchevers, P. Relationship between precipitation phase and air temperature: Comparison between the Bolivian Andes and the Swiss Alps. Hydrol. Sci. J. 2005, 50, 989-997.

52. Braun, L.N.; Lang, H. Simulation of snowmelt runoff in lowland and lower alpine regions of Switzerland. In Proceedings of the Budapest Symposium, Budapest, Hungary, 2-10 July 1986; pp. 125-140.

53. Hottelet, C.; Blažková, Š.; Blčík, M. Application of the ETH snow model to three basins of different character in Central Europe. Nord. Hydrol. 1994, 25, 113-128.

54. Zhang, Y.; Wang, S.; Barr, A.G.; Black, T.A. Impact of snow cover on soil temperature and its simulation in a boreal aspen forest. Cold Reg. Sci. Technol. 2008, 52, 355-370.

55. Caballero, Y.; Chevallier, P.; Gallaire, R.; Pillco, R. Flow modelling in a high mountain valley equipped with hydropower plants: Rio Zongo Valley, Cordillera Real, Bolivia. Hydrol. Process. 2004, 18, 939-957. 
56. Baun, S.D. Frequency Mapping of Maximum Snow Water Equivalent of March Snow Cover over Minnesota and the Eastern Dakotas; NWS Central Region Tech. Memo. CR-113; National Weather Service: Silver Spring, MD, USA. 1998.

57. Pomeroy, J.W.; Gray, D.M.; Brown, T.; Hedstrom, N.R.; Quinton, W.L.; Granger, R.J.; Carey, S.K. The cold regions hydrological model: A platform for basing process representation and model structure on physical evidence. Hydrol. Process. 2007, 21, 2650-2667.

58. Daly, S.F.; Davis, R.; Ochs, E.; Pangburn, T. An approach to spatially distributed snow modelling of the Sacramento and San Joaquin basins, California. Hydrol. Process. 2000, 14, 3257-3271.

59. Auer, A.H., Jr. The rain versus snow threshold temperatures. Weatherwise 1974, doi:10.1080/ 00431672.1974 .9931684$.

60. Bjerknes, J. On the structure of moving cyclones. Mon. Weather Rev. 1919, 47, 95-99.

61. Oliver, V.J.; Oliver, M.B. Weather analysis from single-station data. In Handbook of Meteorology; Berry, F.A., Bolay, E., Beers, N.R., Eds.; McGraw-Hill Book Co.: New York, NY, USA, 1945; pp. 858-879.

62. Fraedrich, K.; Bach, R.; Naujokat, N. Single station climatology of central European fronts Number, time and precipitation statistics. Beitr. Phys. Atmos. 1986, 59, 54-65.

63. Sanders, F. A proposed method of surface map analysis. Mon. Weather Rev. 1999, 127, 945-955.

64. Schultz, D.M. A review of cold fronts with prefrontal troughs and wind shifts. Mon. Weather Rev. 2005, 133, 2449-2472.

65. Lundberg, A.; Halldin, S. Evaporation of intercepted snow: Analysis of governing factors. Water Resour. Res. 1994, 30, 2587-2598.

66. Nuti, R.; Wong, K. Instruments and Observing Methods; WMO/TD-No.1544; World Meteorological Organization: Geneva, Switzerland, 2010.

67. Boudala, F.S.; Rasmussen, R.; Isaac, G.A.; Scott, B. Performance of hot plate for measuring solid precipitation in complex terrain during the 2010 Vancouver Winter Olympics. J. Atmos. Ocean. Technol. 2014, 31, 437-446.

68. Grazioli, J.; Tuia, D.; Monhart, S.; Schneebeli, M.; Raupach, T.; Berne, A. Hydrometeor classification from two dimensional video disdrometer data. Atmos. Meas. Tech. 2014, 7, 2869-2882.

69. Thériault, J.M.; Rasmussen, R.; Petro, E.; Trépanier, J.Y.; Colli, M.; Lanza, L.G. Impact of Wind Direction, Wind Speed, and Particle Characteristics on the Collection Efficiency of the Double Fence Intercomparison Reference. J. Appl. Meteorol. Climatol. 2015, 54, 1918-1930.

70. Yang, D. Double fence intercomparison reference DFIR vs bush gauge for "true" snowfall measurement. J. Hydrol. 2014, 509, 94-100.

71. Garvelmann, J.; Pohl, S.; Weiler, M. From observation to the quantification of snow processes with a time-lapse camera network. Hydrol. Earth Syst. Sci. 2013, 17, 1415-1429.

(C) 2015 by the authors; licensee MDPI, Basel, Switzerland. This article is an open access article distributed under the terms and conditions of the Creative Commons Attribution license (http://creativecommons.org/licenses/by/4.0/). 